\title{
Revisiting the accelerator principle in a world of uncertainty: Some empirical evidence
}

\begin{abstract}
This contribution builds on the accelerator model to produce an investment function in which employment and households' investment are used as proxies for economic activity. This analysis identifies a positive correlation between corporate investment in fixed assets and households' investment in dwellings. Using a panel of 11 OECD countries for the period 1970-2010, the results also confirm that oil prices and interest rates may dampen firms' investment in fixed assets. An interesting feature of this investment function is that it accounts for uncertainty.
\end{abstract}

Keywords: Investment, Uncertainty, Accelerator, Panel Data

JEL Classification: B22, C23, E22 


\section{Introduction ${ }^{1}$}

The aim of this paper is to produce an investment function based on the accelerator principle that includes employment and the rate of growth of investment in dwellings to approximate the level of economic activity. Our model also focuses on the role of oil prices in the current economic situation where energy efficiency and renewable energy are key elements in the transition to a low-carbon economy. Additionally, this investment function also examines whether there is some evidence of interest rates driving firms' investment.

This paper builds on the approach introduced by Lavoie et al. (2004) to account for uncertainty and conventions in the explanation of capital accumulation. Specifically, the current piece of research employs the approach presented in Arestis et al. (2012) to include uncertainty. Although both approaches employ the Hodrick-Prescott filter (Hodrick and Prescott, 1980) to approximate the 'conventional' knowledge, there are differences in the way in which the conventional level of the variables is included within the model. ${ }^{2}$ In particular, this contribution moves beyond the Arestis et al. (2012) findings by exploring other proxies of the level of the economic activity, which have been ignored in the existing literature, such as employment and dwelling investment. Traditionally, capacity utilisation, which gives an indication of the volume of capital stock that is used in the economy, has been utilised to approximate the level of economic activity. However, this variable only refers to one factor of production, i.e. capital. In this context, an interesting issue to be explored is whether the existence of 'idle' labour, i.e. unemployment, could act as a constraint to investment. In addition, this paper also examines whether the activity of the housing market could be another driver of the accumulation process. This is so in view of the study by Leamer (2007), which suggests that housing cycles lead to business cycles. For the purpose of this paper, an alternative discussion of the role of oil prices in the investment decision is also provided, i.e. oil is treated as another productive factor rather than a proxy for political uncertainty.

Subsequently our theoretical proposition is investigated empirically in a sample of 11 OECD economies over the period 1970-2010. Specifically we employ the Within-Group estimation to model fixed effects, GLS to estimate random effects, the Panel Corrected

\footnotetext{
${ }^{1}$ The authors are grateful to the editor and also to the four anonymous referees for helpful comments on an earlier version of this manuscript. Any remaining errors and omissions are our own responsibility.

${ }^{2}$ More specifically, in Arestis et al (2012) uncertainty is included in the model by calculating the deviation between the current level of the relevant variable and its conventional level, while in Lavoie et al. (2004) conventional levels are considered as a variable itself or use as a component of some explanatory variables.
} 
Standard Errors technique (PCSE) and fixed effects (within) estimations with the Driscoll and Kraay standard errors.

The remainder of this contribution is organized as follows. Section 2 presents the investment function that we propose for the purpose of this contribution. Section 3 focuses on the econometric techniques utilised. Section 4 presents the econometric results, while Section 5 interprets and discusses further the derived estimates. Section 6 summarises and concludes.

\section{The investment function}

\subsection{Revisiting the accelerator model}

The starting point of this contribution is the traditional accelerator model of investment, which is presented in equation 1:

$I=\beta_{0}+\mu\left(Y_{t}-Y_{t-1}\right)=\beta_{0}+\mu\left(\Delta Y_{t}\right)$

where $I$ stands for investment in fixed capital assets, $Y$ is output, and $\mu$ represents the ratio of capital-to-output.

It is well-known that the accelerator principle assumes that firms undertake new investment projects to adapt their productive capacity to a new situation where they need to satisfy higher effective demand. Specifically, the flexible accelerator model improves the basic accelerator principle by considering the existence of an optimal or desired capital-tooutput ratio (Koyck, 1954). Despite the importance of this principle, several criticisms have been pointed out by the existing literature such as its asymmetrical behaviour and its mechanicism. ${ }^{3}$ Futher criticisms are its inability to account for technical change and expectations regarding future demand.

Equation (1) can be transformed by expressing the variables as a ratio to output. ${ }^{4}$ As a result, the endogenous variable of our model is defined as the investment-to-output ratio, $\frac{I}{Y}$, instead of the traditional rate of accumulation, which is defined as $\frac{I}{K}$ (see also Lee et al., 2012). This transformation has interesting properties in terms of its interpretation. More

\footnotetext{
${ }^{3}$ It exhibits an asymmetric behaviour, due to the fact that this principle explains better investment decisions where the disequilibrium between the desired capital-to-output ratio and effective capital-to-output ratio is caused by a shortage of installed capital rather than a surplus of capital.

${ }^{4}$ This transformation is helpful to cope with the lack of consistent and homogeneous data on private capital stock.
} 
specifically, the coefficients, which will be estimated to test our testable hypothesis will be $\eta$ times those that we could find in the case of considering the rate of accumulation as the endogenous variable of this flexible accelerator model (Dehn, 2000, also adopts a similar approach). The resulting model is shown in equation (2):

$$
\frac{I}{Y}=\mu_{0}+\mu_{1} \hat{Y}
$$

where $\hat{Y}$ captures the rate of growth of output, and the other symbols have the same meaning as in equation (1).

In general terms, investment decisions are taken in a context of uncertainty, which enhances the role of the animal spirits. Uncertainty can emanate from several sources such as economic factors, political regimes, environment, etc. In this context, agents' difficulties to form accurate expectations about the future have been emphasised by the financial turbulence, which started in August 2007 and led to the 'great recession' (The Economist, 2012). Uncertainty is particularly relevant in the case of investment in fixed capital assets, where there are high sunk costs. The irreversibility of the investment decision results in the value of 'waiting' to improve the imperfect and limited information that businessmen have when they embark on a new project. This element becomes crucial in those cases where the project involves the adoption of pioneering technologies; for example, investment in renewable energy, or when there is room for policy makers to tackle market failures.

In particular, our model assigns an important role to the acceleration principle, which accounts for expectations about future aggregate demand, $\hat{Y}$, which are proxied by the rate of growth of effective demand in the recent past. However, this continuity just creates the general context where the animal spirits can act spontaneously. The animal spirits $\grave{a}$ la Keynes are captured in equation (2) by means of the 'intercept', $\mu_{0}$, as discussed extensively in Dutt (1984).

In this context, two different proxies for the level of economic activity are included in order to improve businessmen' knowledge of the current stage of the economy; these are the rate of employment and the volume of households' investment. In this context, a relevant element that needs to be discussed is the role of conventions. ${ }^{5}$ From a Keynesian

\footnotetext{
5 See, also, De Melo Modenesi et al. (2013) for further discussion of alternative views of the notion of 'convention'. De Melo Modenesi et al. (op. cit.) concentrate on the Keynesian and French approaches. More specifically, the Keynesian view (Keynes, 1936; Davidson, 2002) identifies conventions with a 'mechanism'
} 
view conventions are understood as a mechanism to help individuals to define their expectations in a non-ergodic world where mathematical and statistical analyses are not the ultimate 'tool' to help individuals to take their economic decisions. In this context, it is more realistic to assume that this decision rule or mechanism will be 'connected' to the evolution of the economy in the recent past. The notion of self-fulfilling prophecies (Merton, 1968), which has been extensively applied by Shiller (2007) in the context of housing economics, is also applicable to this discussion and provides some justification for this assumption.

In our analysis, the construction of a proxy for conventions is based on the HodrickPrescott filter (Hodrick and Prescott, 1980). ${ }^{6}$ This approach is compatible with the French School view (Dequech, 2009; 2011) in the sense that this knowledge is available and 'shared' by all individuals since it is based on the past and does not include personal judgements. Additionally, this filter, which allows the trend component to vary through time, also presents the dynamic behaviour that is implicit in the notion of conventions as highlighted by Dequech (2011). This can be interpreted as a reflection of how individuals need to revise continuously their expectations.

\subsection{Alternative proxies for the level of economic activity}

We assume an economy with 3 productive factors: labour, capital, and an energy commodity. The inclusion of labour in the productive process suggests the construction of an indicator for the level of economic activity, based on the proportion of the employed population. In this context, businessmen's investment plans will be less ambitious when they have to cope with a decline in demand. The evolution of the share of potential workers, who are currently employed, requires further analysis. Specifically, workers play a double role in the economy, i.e. they are a source of demand and also a productive factor, whose cost impacts firms' profitability. ${ }^{7}$ Turning our attention to the labour market, the

\footnotetext{
that individuals can use to deal with the existence of uncertainty in their economic decision-making process. The French School (Dequech, 2009) understands conventions as a common knowledge, which emerges in response to uncertainty.

${ }^{6}$ The Hodrick-Prescott filter (Hodrick and Prescott, 1980) permits the researcher to decompose time series into their trend and cyclical components. More specifically, the Hodrick-Prescott filter (op. cit.) isolates the trend and the cyclical components of a particular time series; and works by minimizing the square of the deviations from the trend and by penalising changes in the acceleration of the trend of the time series. In particular, we asume that businessmen's expectations, i.e. businessmen's conventional knowledge, are based on the trends followed by the variables in the past.

${ }^{7}$ An alternative interpretation of the relationship between investment and employment is provided by Skott and Zipperer (2010). Skott and Zipperer (op. cit) suggest a negative relationship between both in those cases
} 
following question needs to be addressed: is hysteresis in the labour market strong enough to change the normal level of employment so rapidly that the share of population that is actively involved in the labour market can constrain accumulation and growth? The study by Nickell and Nunziata (2002) highlights the upward trend that has been exhibited by involuntary unemployment in the vast majority of the developed countries since 1960. The inclusion of employment permits businessmen to approximate the level of economic activity through time, which substitutes for the traditional indicator, i.e. capacity utilisation.

The evolution of employment constitutes an additional source of information to 'feed' expectations about future demand, since higher levels of employment will lead the economy to a position characterised by higher consumption. This mechanism can also be reinforced by the existence of a positive relationship between employment and wages, i.e. high levels of employment could push wages up in a non-linear way. In this context, entrepreneurs' expectations about the level of employment could be captured by means of the normal rate of employment. Additionally, we need to take into account that a decrease in the current rate of employment, i.e. an increase in the level of unemployment over the conventional level, is understood by firms as a negative signal of the market, since they have to face a decline in expected demand. This means an increase in the degree of uncertainty with which firms need to confront. Despite the availability of public benefits unemployed workers will have to alter their consumption habits according to their new situation. Introducing this element in equation (2), we obtain the investment function shown in expression (3):

$$
\frac{I}{Y}=\mu_{0}+\mu_{1} \hat{Y}+\mu_{2} d N
$$

where the symbols are as in (2) with the exception of $d N$, which stands for the deviation of the level of employment from its conventional level. ${ }^{8}$

where the workers' bargaining power is so strong that businessmen's animal spirits are depressed. In other words, animal spirits would be depressed since firms need to keep or increase their profit share so that they can have rising internal resources, which permit them to finance their investment projects. However, for the purpose of this contribution we do not assume this negative effect since this could take place just in a 'fullemployment' scenario.

8 The deviation of employment from its conventional level, $d N$, is defined according to the formula presented in equation (4): 
Moreover, an important driver of the business cycle, which needs to be included, is the evolution of households' investment (see, Learmer, 2007, for further details). It has been extensively discussed that there are important 'pulling-effects' associated with construction activities in terms of employment creation. ${ }^{9}$ To make the point, we refer to the UK case, where construction accounts for $7 \%$ of total employment (Spada, 2009). The relevance of the construction sector as one of the key industries in developed economies is also notorious in terms of generation of value added. More specifically, the UK construction sector generates $6.3 \%$ of the UK total output (Spada, op. cit.). This percentage is even higher when other activities related to construction, such as real estate, engineering, and architecture services, are considered. Other interesting examples of the importance of the construction sector in the development of the overall economy are Ireland, the United States and Spain, among others. It is well documented how problematic the period of economic slowdown for these economies was after the collapse of their housing markets in 2007/2008 (Gattini and Ganoulis, 2012; Arestis and González-Martínez, 2015). This discussion justifies our choice for the rate of growth of investment in dwellings as a proxy for changes in the level of economic activity in view of its important contribution to the economy at the macro level in terms of aggregate demand, employment and production.

For simplicity, our model assumes an economy without a public sector, where investment is undertaken by firms, i.e. investment in fixed assets, or by households, i.e. investment in dwellings. We may note that in the short run, a possible crowding-out effect between investment in capital assets and investment in properties could occur if firms prefer to speculate with land and housing assets instead of increasing their productive capacity. Gan (2007) focuses on the Japanese economy and suggests that those companies that hold land are more sensitive to the consequences of housing bubbles than those, which do not own this kind of asset. Along the same vein, Chaney et al. (2012), using data for the United States during the period 1993-2007, report that an increase in firms' collateral, due to hikes in housing prices, provoked a rise in firms' investment since real estate assets

$$
d N_{i, t_{-1}}=\frac{N_{i, t_{-1}}-N^{*}}{N^{*}}
$$

where $N$ is the effective value of the variable (employment in this particular case) and $\mathrm{N}^{*}$ is its normal or conventional value, i.e. the normal level of employment.

${ }^{9}$ The effects that result from corporate investment and households' investment are very different. The former contributes to create productive capacity and long-term growth, while the latter has just positive effects on growth in the short run. 
were, and still are, a considerable part of the total amount of the assets that they own. Chaney et al. (op. cit.) also justify this finding in view of the following arguments: (a) there is a positive correlation between real estate prices and the existence of investment opportunities, since an increase in firms' investment provokes a rise in the demand for goods and labour in the local market; this means an acceleration of economic activity and rising income that fuels demand for dwelling and induces hikes in the prices of the real estate market; and (b) the decision to own these kind of assets is also related to the possibility of investment. The relationship between investment and real estate is reinforced under the presence of credit constraints. ${ }^{10}$

Moreover, a high level of activity in the housing market could induce a switch in the investment path. Gete (2010) suggests that an increase in preferences for housing, provokes a relocation of productive inputs towards housing production, which means increasing imports of non-housing goods. In addition to the effects described above, it is noticed that an increase in corporate investment has positive effects on economic growth, since it means an increase in effective demand, which provokes a rise in income and a decline in unemployment. These two propositions improve housing affordability, which fuels the demand for housing. The inclusion of this new explanatory element in equation (3) produces equation (5):

$$
\frac{I}{Y}=\mu_{0}+\mu_{1} \hat{Y}+\mu_{2} d N+\mu_{3} D \hat{W}
$$

where the variables are as before with the exception of $D \hat{W}$, which stands for the rate of growth of households' investment in dwelling.

\subsection{External finance and the investment decision}

The impact of the cost of external finance on investment also needs to be included since frequently new investments require agents to get into debt to obtain the amount of capital that they need to finance the relevant project. ${ }^{11}$ This is applicable to any type of

\footnotetext{
${ }^{10}$ Moreover, the dynamics of the housing market are also an important determinant of households' consumption via 'wealth' and 'collateral' effects (Miller et al., 2011).

${ }^{11}$ See, also, Stockhammer and Grafl (2010) for further discussion and empirical evidence of the impact of interest rates on investment and the accumulation path. This branch of the economic literature highlights the existence of an income redistribution process, which emanates from changes in interest rates. Initially, the mentioned process affects aggregate consumption and subsequently investment.
} 
investment decision without considering the kind of individual who undertakes the investment, i.e. corporate investment or households ' purchases of dwellings. ${ }^{12}$ Focusing on corporate investment we could expect that rising interest rates will discourage some companies from investing since the project will not be profitable enough to repay the debt and generate extraordinary profits. ${ }^{13}$

Chetty (2007) discusses alternative effects of changes in the rate of interest on firms' investment. More specifically, Chetty (op. cit.) suggests that a company can postpone its investment decision, in a context of high borrowing costs, in order to obtain better information about the profitability of a particular project. However, there is a cost related to postpone the execution of an investment project; i.e. firms will be forced to keep their outstanding debt for longer, which provokes an increase in their interest rate payments. Alternatively, Chetty (2007) identifies an accelerating effect of rising interest rates since firms would be more interested in investing rapidly in order to reduce their interest burden and materialise expected profits as soon as possible. In view of this discussion, the effect of rising interest rates on investment could be uncertain, and its sign and intensity would be conditioned by the presence of other factors such as optimistic businessmen's expectations, the existence of liquidity constraints or high credit standards in the banking system. However, we adopt a 'traditional' view of the relationship between these two variables and assume that a depressing effect on investment is more likely to emanate in the context of uncertainty, imperfect information and credit constraints. This is so since generally rising interest rates are utilised jointly with other instruments such as the tightening of eligibility criteria, which could make it more difficult for firms to get into debt. The inclusion of this variable in the investment function proposed in equation (5) produces the following relationship:

$$
\frac{I}{Y}=\mu_{0}+\mu_{1} \hat{Y}+\mu_{2} d N+\mu_{3} D \hat{W}-\mu_{4} i
$$

\footnotetext{
${ }^{12}$ Myers (1984) and Fazzari et al. (1988) also suggest that firms utilise intermediate finance in those cases where it is not possible to finance investment by means of internal resources, which are the cheapest alternative. A similar approach that focuses on households' investment in dwellings is presented in the 'financial accelerator' approach of Bernanke et al. (1996).

${ }^{13}$ Interest rates are an additional and important determinant of the user cost of capital. The latter is also determined by the price of capital goods, depreciation and taxation (Jorgenson, 1963).
} 
where the meaning of the variables is as in equation (5) with the exception of $i$, which stands for the long-term real rate of interest. ${ }^{14}$

\subsection{Importance of energy prices}

As advanced earlier, we treat energy as another production factor, which is added to the two traditional productive factors, i.e. capital and labour. For simplicity our model assumes just the existence of a single energy commodity, i.e. oil. In general terms, an improvement in the efficiency of those inputs required in the production process, could be achieved by two different possibilities: (a) by reducing the amount of inputs, which end up as waste at the end of the production process; or (b) by reducing the flows of inputs, which are required to produce a given level of output. The only way in which firms can improve their current 'level' of efficiency is by means of new technology; in other words, they invest in new capital assets, which can produce more with a smaller volume of resources. Our testable hypothesis suggests that rising oil prices can generate an incentive to invest in 'green-technologies' and energy efficiency. ${ }^{15,}{ }^{16}$ However, green and non-green investments need to be considered separately. That distinction needs to be made since it could be the case that the overall impact of oil prices on investment is negative. This possibility would suggest that the positive effect on green investment is not enough to offset the negative effect on non-green investment. However, this hypothesis cannot be tested due to lack of data.

Improvements of energy efficiency have become paramount to reduce oil and other energy-sources deployment in a context where firms need to take into account not only oil prices, but also those additional costs that they would face if they produced a higher volume of pollutants. This is so due to the implementation of measures such as the EU Emission Trading Scheme (EU ETS). ${ }^{17,18}$

\footnotetext{
${ }^{14}$ The choice of a long-run interest rate is entirely compatible with Keynes's (1936) relevant contribution, which acknowledges the role of expectations in the determination of this kind of interest rate.

${ }^{15}$ See, also, Shahbaz at al. (2012) for further discussion on the relationship between energy demand and economic growth and relevant empirical evidence in the case of Pakistan.

${ }^{16}$ See, also, Arouri (2011) and Reboredo and Rivera-Castro (2013) for further details on the implications of oil prices in financial markets.

${ }^{17}$ De Manuel (2011) highlights the lack of efficiency in the EU ETS, in the primary market for allowances, in view of the over allocation, which took place during the first period of this scheme. De Manuel (op. cit.) also discusses extensively the effects associated with the so-called 'carbon leakage'. The presence of this phenomenon implies that companies can delocalise their productive process to other areas with a more lax regulation. If that is the case, a slowdown of the accumulation path of those economies, which joined the agreement, could take place. However, the quantification of the impact of this phenomenon on investment goes beyond the scope of this paper.
} 
This new objective is also crucial under the implementation of a carbon tax, which levies the carbon content of fuels. Both alternatives to mitigate climate change and favour the transition towards a low-carbon economy imply an increase in productive costs that reduces profits and also limits the possibilities of self-finance investment in the future. In this context, there are two different and conflicting effects, which emanate from rising oil prices. On the one hand, an increase in the price of this commodity would favour a switch to less oil-intensive technologies. This affects investment positively. Alternatively, an increase in oil prices 'today' means a decline in profitability. The latter effect prevails in the short and medium run, while the mentioned positive effect needs a longer-time horizon to operate due to the presence of high-sunk costs. ${ }^{19}$ In principle, businessmen will not invest in new technologies unless high oil prices are maintained throughout time and become the new 'business-as-usual' scenario. No certain hypothesis can be postulated regarding the behaviour of future oil prices due to the high volatility that they have exhibited historically. Introducing the impact of oil prices and retaining the assumed linear specification, our theoretical premise is summarised as follows:

$$
\frac{I}{Y}=\mu_{0}+\mu_{1} \hat{Y}+\mu_{2} d N+\mu_{3} D \hat{W}-\mu_{4} i \pm \mu_{5} d \Phi+\xi
$$

where $\mu_{i}$ are the coefficients, which are going to be estimated, with $\xi$ being a random error term. All the variables are as in equation (6) with the exception of $d \Phi$, which stands for the deviation of oil prices from their conventional level. ${ }^{20}$

\section{Econometric analysis}

For the purpose of this study, four techniques are applied to estimate the relationship shown in equation (7): (a) the Within-Group estimation to model fixed effects;

\footnotetext{
${ }^{18}$ See, also, Ouchida and Goto (2014), for further discussion on the impact of emission tax policies and their implications in terms of R\&D.

${ }^{19}$ See, also, Kilian (2009) for further explanations of the impact of oil price fluctuations on the US economy. Kilian (op. cit.) analyses the evolution of oil prices by considering the following kind of shocks: (a) oil supply shocks; (b) changes in global activity, which fuel oil demand; and (c) oil demand shocks, which affect only the oil market. Moreover, Millard and Shakir (2013) study the impact of oil-price shocks in the UK economy by means of the time-varying parameter structural vector autoregression (TVP-SVAR) approach.

${ }^{20}$ The deviation of oil prices, $d \Phi$, from their conventional level, is calculated in the same way as that of the deviation of employment from its conventional level.
} 
(b) the GLS to estimate random effects; ${ }^{21}$ (c) the Panel Corrected Standard Errors technique (Beck and Katz, 1995); and (d) the fixed effects (within) estimator with the Driscoll and Kraay standard errors (Driscoll and Kraay, 1998; Hoechle, 2007). ${ }^{22}$

We begin with the within-group fixed effects estimator and the GLS technique. Equation (8) shows the fixed-effects specification and equation (9) provides the randomeffects method.

$y_{i t}=x_{i t} \beta+\alpha_{i}+\varepsilon_{i t}$

$y_{i t}=x_{i t} \beta+\mu+u_{i}+\varepsilon_{i t}$

where $x_{i t}$ denotes the set of exogenous variables, $y_{i t}$ collects the set of dependent variables, $\beta$ are the estimated coefficients, $\alpha_{i}$ reflects the individual-specific effects, and $\varepsilon_{i t}$ is the random error term. In equation (9), $\mu$ is a constant term, while there is a compound error, $u_{i}$ $+\varepsilon_{i t}$

The fixed-effects method reflects temporary effects for each individual variable of the sample, i.e. this technique permits to control changes in all the variables of each country that vary between $t$ and $t+1$. The random-effects method considers that individual effects are distributed randomly to each individual variable. The GLS method usually assumes that the variance/covariance matrix, $\Omega$, is known or it is possible to approximate it. However, Beck and Katz (1995) consider that the previous method produces inaccurate standard errors of the parameters that are estimated. Their alternative is to produce several clusters using the residuals of the model, as in $\hat{\varepsilon}_{1}, \hat{\varepsilon}_{2}, \ldots \hat{\varepsilon}_{N}$ and obtain the following matrix:

$\mathrm{E}=\left[\begin{array}{lllll}\hat{\varepsilon}_{1} & \hat{\varepsilon}_{2} & \ldots & \hat{\varepsilon}_{N-1} & \hat{\varepsilon}_{N}\end{array}\right]$

Equation (11) presents the panel corrected variance/covariance, where $\hat{\Omega}$ is calculated using the 'Kronecker product' ${ }^{23}$ as formula (12) shows:

\footnotetext{
${ }^{21}$ See, Baltagi (2006), for further explanations of the Within-Group estimator and the GLS technique.

${ }^{22}$ Some preliminary estimates were conducted by means of the linear generalized method of moments (Arellano and Bond, 1991), i.e. difference GMM, and the system GMM (Arellano and Bover, 1995; Blundell and Bond, 1998). However, these techniques did not perform well since suitable instruments were not found. A possible explanation of this fact may be related to the size of the sample since GMM performs better in large-sized samples.
} 
$P C S E \operatorname{Var}(\hat{\beta})=\left(X^{\prime} X\right)^{-1} X^{\prime}(\hat{\Omega}) X\left(X^{\prime} X\right)^{-1}$

$\hat{\Omega}=\frac{(E E)}{T} \otimes I$

In this case, the estimated coefficients are more accurate due to the fact that they compute several observations of the error term in order to obtain the error variance. The PCSE estimator is an appropriate technique when the time dimension of the panel, $T$, is much larger than the number of countries, which compound the cross-section $N$.

However, a recent contribution (Reed and Webb, 2010) suggests that under certain circumstances the PCSE estimator does not perform as well as discussed in Beck and Katz (1995). These conditions are the following: (a) when the time dimension of the data is relatively short; (b) when the exogenous variables display persistence; and (c) when there is serial correlation between the errors. Kristensen and Wawro (2003) also question the validity of this method in those cases where the autocorrelation between the residuals is high. In view of these arguments and the presence of autocorrelation we apply the PCSE estimator just for comparative purposes.

Subsequently, we utilise the fixed effects (within) estimator with Driscoll and Kraay (1998) standard errors, which constitute the best technique to estimate the suggested model. Driscoll and Kraay (op. cit.) develop a nonparametric covariance matrix estimator, which permits one to obtain standard errors that are consistent under the violation of some of the basic assumptions of the linear regression model, i.e. the presence of heteroskedasticity and autocorrelation. These standard errors are also robust to general forms of spatial and temporal dependence. This is a considerable improvement in comparison to other approaches to obtain standard errors such as Newey and West (1987) and Arellano (1987).

A fixed effect (within) estimation with Driscoll and Kraay (1998) standard errors could be implemented as shown in equations (13) and (14). Hoechle (2007) develops a STATA routine, which permits the use of this approach on unbalanced panels. ${ }^{24}$ Hoechle (op. cit.) describes the fixed effect (within) estimation with Driscoll and Kraay (1998) standard errors as a process in two steps. In the first step, the variables under consideration

\footnotetext{
${ }^{23}$ This is derived by multiplying a chosen term in the matrix on the left-hand side by the matrix on the righthand side, and place the result into the matrix on the left-hand side for the chosen element. The Kronecker product is indicated by the symbol $\otimes$.

${ }^{24}$ STATA/SE 11 (StataCorp, 2009) is the statistical package that we have employed to estimate the econometric regressions of this contribution.
} 
are within-transformed ones. The rationale for this transformation is to obtain those variables, which make the within-estimator equivalent to the OLS estimator of the expression (13):

$\tilde{y}_{i t}=\alpha_{i}+\tilde{x}_{i t} \beta+\tilde{\varepsilon}_{i t}$

where $\tilde{y}_{i t}, \tilde{x}_{i t}$ and $\tilde{\varepsilon}_{i t}$ are the transformed variables.

In the second step, the model presented in (13) is estimated by Driscoll and Kraay (1998) standard errors for pooled OLS estimation. More specifically, the parameters are estimated as the square roots of the diagonal elements of the following robust covariance matrix:

$\widehat{\beta}=\left(x^{\prime} x\right)^{-1} x^{\prime} y$

$V(\hat{\beta})=\left(x^{\prime} x\right)^{-1} \Gamma\left(x^{\prime} x\right)^{-1}$

where $\Gamma^{\prime}$ is defined as presented in Newey and West (1987). ${ }^{25}$

The existence of country-specific features in the accumulation of private productive capital for each country provides information about diverse circumstances; for example, the degree of indebtedness, liquidity problems, the state of confidence of the entrepreneur, the animal spirits, etc. Consideration of all these features is important in order to capture the diversity of the countries involved in our study. This diversity means differences in regulation, financial institutions, political regimens, historical development of the country, social structures, technological conditions, etc.

\section{Empirical evidence}

Before moving to the presentation of our empirical results some details on the sample that has been analysed are provided. Our dataset starts in 1970 due to the lack of homogeneous and consistent data prior to this period for some of the time series that are required. The data series under consideration end in 2010. This time horizon seems to be

\footnotetext{
${ }^{25}$ See, also, Hoechle (2007) for further details on the implementation of this method.
} 
more reasonable than ending in 2014 in order to identify a single path of accumulation in view of the 2009 financial crisis and the 'great recession', which impacted hugely upon the development of the economy. In other words, our sample spans 1970-2012 to capture the fact that some investment projects, which had been under development prior to 2009 were not interrupted and were concluded by 2010. Our dataset comprises annual data for the following economies: Australia, Austria, Belgium, Canada, Denmark, France, Germany, Italy, Spain, the United Kingdom and the United States.

In order to produce the econometric results, which are shown in Table 1, we begin the estimation process by considering a general specification of our model in which two lags for each explanatory variable are included, although the final specification only includes those variables which are significant, which are all lagged once. ${ }^{26}$ This time horizon allows us to capture the delay between the time in which the firm decides to invest and the time when this investment is an active part of the production process. The consideration of a time horizon of 2 years is consistent with the existing body of literature (Baddeley, 2003). Moreover, the significance of these lags is a reflection of the fact that firms could consider shorter time horizons when taking their decision and assume that the very near future will exhibit some continuity with the current situation. In other words, the longer the period under consideration, the higher the degree of uncertainty that the company would have to face.

In order to produce the relevant estimates the 'general-to-specific' modelling approach (Hendry and Richard, 1983) has been applied. In order to preserve space, Table I only reports those models where all the variables are significant.

The first two columns in Table 1, which display Models I and II, present the withingroup fixed-effects estimators and the GLS estimators respectively. These two regressions can be considered as preliminary estimations that permit us to identify the presence of individual effects, and subsequently, the prevalence of fixed effects over random effects. Model III is estimated by PCSE. Then, Model IV is estimated by means of the the Driskroll and Kraay (1998) standard errors estimator. ${ }^{27}$

\footnotetext{
${ }^{26}$ The stationarity of the data that we employ has been checked by using three different unit root tests. Specifically, we apply the Im-Pesaran-Shin (Im et al, 2003) test, which assumes an individual unit root process, the Fisher-augmented Dickey-Fuller (Choi, 2001) test and the Fisher-Phillips-Perron (Choi, 2001) test; the latter considers an individual unit root process. All of these tests confirm stationarity of the data, which prevents us from applying cointegration techniques. The results of these unit roots tests are available from the authors upon request.

${ }^{27}$ The potential existence of multicollinearity issues among eeconomic growth, employment and investment in housing has been studied. Specifically, correlation coefficients among the variables are around 0.30 or
} 
Table 1

Econometric results for accumulation model (1970-2010)

\begin{tabular}{|c|c|c|c|c|}
\hline Equation & MODEL I & MODEL II & MODEL III & MODEL IV \\
\hline Method & $\mathrm{FE}$ & GLS & PCSE & FE DK \\
\hline Dependent & $\mathrm{I} / \mathrm{Y}$ & $\mathrm{I} / \mathrm{Y}$ & $\mathrm{I} / \mathrm{Y}$ & $\mathrm{I} / \mathrm{Y}$ \\
\hline Constant & $0.1791 *(0.0018)$ & $0.1796 *(0.0050)$ & $0.1760 *(0.0025)$ & $0.1791 *(0.0019)$ \\
\hline $\mathrm{I} / \mathrm{Y}(\mathrm{t}-1)$ & - & - & - & - \\
\hline$\breve{Y}(\mathrm{t}-1)$ & $0.3209 *(0.0391)$ & $0.3220 *(0.0393)$ & $0.3631 *(0.0546)$ & $0.3209 *(0.0445)$ \\
\hline $\mathrm{dN}(\mathrm{t}-1)$ & $0.0001 * *(0.0000)$ & $0.0001 * *(0.0000)$ & $0.0002 *(0.0000)$ & $0.0001 *(0.0000)$ \\
\hline DW $(\mathrm{t}-1)$ & $0.0327 *(0.0075)$ & $0.0330 *(0.0075)$ & $0.0456 *(0.0120)$ & $0.0327 *(0.0080)$ \\
\hline $\mathrm{i}(\mathrm{t}-1)$ & $-0.1776 *(0.0268)$ & $-0.1771 *(0.0270)$ & $-0.1642 *(0.0372)$ & $-0.1776 *(0.0458)$ \\
\hline $\mathrm{d} \Phi(\mathrm{t}-1)$ & $-0.0090 * *(0.0039)$ & $-0.0090 * *(0.0039)$ & $-0.0075^{* * *}(0.0046)$ & $-0.0090 * *(0.0042)$ \\
\hline Number of observations (countries) & $419(11)$ & $419(11)$ & $419(11)$ & $419(11)$ \\
\hline R-squared & 0.3806 & 0.3806 & 0.2351 & 0.3806 \\
\hline F test (p-value) & $49.5200(0.0000)$ & - & - & $76.3600(0.0000)$ \\
\hline Wald test of joint significance (p-value) & - & $246.0500(0.000)$ & $185.9600(0.0000)$ & - \\
\hline$\rho$ & 0.6352 & 0.5282 & - & - \\
\hline $\begin{array}{l}\text { Modified Wald test for groupwise heteroskedasticity } \\
\text { Breusch and Pagan Lagrangian multiplier test for random } \\
\text { effects }\end{array}$ & $115.9390(0.0000)$ & $14.6100(0.0001)$ & - & - \\
\hline Wooldridge test for autocorrelation in panel data & $145.1980(0.0000)$ & & & \\
\hline Pesaran's test (p-value) & $7.0120(0.0000)$ & & & \\
\hline Breusch-Pagan LM test of independence & $32.9200(0.0005)$ & & & \\
\hline Hausman test & $58.0700(0.0000)$ & & & \\
\hline
\end{tabular}

Note: $* * *$ and $* * *$ indicate statistical significance and rejection of the null at the 1,5 and $10 \%$ significance levels, respectively. Numbers in parentheses, in the case of the variables, show the standard errors. In the case of the F-tests, the corresponding p-values are reported.

The diagnostics/statistics, which validate these econometric results, are reported in the lower part of Table I. The models reported in Table I include an intercept, which is positive and significant. In all the cases the null hypothesis of the Wald test of joint significance is rejected, which suggests the acceptance of the estimated parameters. The Rsquared is also reported. In particular, the lowest value of the R-squared is exhibited by Model III (0.2351). In the other three cases, the models are able to explain around $39 \%$ of the changes in the investment-to-capital ratio. The Breusch and Pagan Lagrangian multiplier test for random effects suggests that the fixed effects estimator is more

below in the vast majority of the countries that we have considered. However, correlation is in the range of 0.6-0.7 in the case of France, Italy and Germany. In order to check whether there is enough variability among economic growth, residential investment and employment, several plots of these variables have been produced in the case of France, Italy and Germany. The plots are available from the authors upon request. 
appropriate than the GLS estimator. Moreover, a modified test for heteroskedasticiy is applied to the fixed effect regression. This test confirms the rejection of the hypothesis of homoskedasticity of the residuals. Finally, the Breusch-Pagan LM test of independence reveals the existence of cross-sectional dependence, which suggests the estimation of the model by means of the fixed effects of the Driskroll and Kraay (1998) standard errors estimator. The existence of cross sectional dependence is also confirmed by the Pesaran's test (Pesaran, 2004; see, also, De Hoyos and Sarafidis, 2006). Additionally, the Wooldridge test for autocorrelation in panel data is also applied (Wooldridge, 2002). The result of this test highlights the presence of serial correlation in the residuals. ${ }^{28}$

The results of these tests permit us to validate our estimations and the technique employed to obtain them. These estimates are further discussed in the section that follows.

\section{Interpretation of the empirical results}

We begin our discussion with the first column (Model I), which reports a positive impact on accumulation of the expected rate of growth of demand (0.3209), of the level of employment (0.0001), and of the activity of the construction sector in $t-1$ (0.0327). This specification, which was estimated by the within-group fixed effects estimator, also shows how a rise in the cost of external finance in $t-1(-0.1776)$ and the presence of increasing uncertainty, which is also proxied by the evolution of oil prices $(-0.0090)$ in the previous period, dampen current investment.

The GLS estimates (Model II) also points to expectations about future demand as the main driver of the investment decision (0.3220). This positive effect is reinforced by the positive impact on demand, which emanates from the construction sector (0.0330), and the direct effect that the level of employment has on businessmen's expectations (0.0001). This model also captures a negative effect of the cost of external finance and the presence of oil price shocks (-0.1771 and -0.0090 respectively). The Hausman's (1987) test suggests the fixed effects estimator, i.e. Model I, is preferred to Model II. The percentage of the variance, which is caused by differences across the panels under consideration, is also reported in Table I (64\% in the case of Model I and 53\% in the event of Model II).

Model III, which is estimated by means of PCSE, portrays a positive relationship between the rate of growth of GDP in $t-1$ and investment (0.3631). It also shows how

\footnotetext{
${ }^{28}$ The presence of autocorrelation does not imply a bias in our econometric results since the PCSE and the fixed-effects of the Driskroll and Kraay (1998) estimators produce robust standard error estimates for linear panel models.
} 
increasing borrowing costs dampen accumulation (-0.1642). A positive influence of the real estate sector on investment is also found (0.0456). Another variable, which accelerates capital accumulation, is deviations of employment in $t-1$ (0.0002). Additionally, Model III shows an inverse relationship between rising oil prices and accumulation (-0.0075).

Model IV is the preferred static relationship, since the relevant independent variables are significant and have the correct sign. Specifically, Model IV captures a positive impact on expectations about future demand (0.3209), the rate of growth of households' investment (0.0327) and employment deviation on investment (0.0001). This specification also reports a negative effect of interest rates (-0.1776). As expected, a sharp increase in the price of the energy commodity depresses investment (-0.0090). This is due to the fact that this increase in the costs reduces profits, unless firms pass it on to their customers. This negative effect is the one that would appear in a 'business as usual' scenario where policy makers would not encourage further efforts to mitigate the effects of climate change.

The estimates discussed in this section clearly support the testable hypotheses discussed above. This study emphasises the explanatory power of the accelerator principle as modified in this contribution. In other words, entrepreneurs' expectations about future demand exert the strongest positive impact on accumulation. A weak effective demand will discourage businessmen to increase capacity even in those cases where internal finance is available. Moreover, our analysis identifies a positive correlation between corporate investment in fixed assets and households' investment in real estate assets. The residential construction sector constitutes an important source of demand for domestic production, and also plays a relevant role in terms of 'jobs' creation. In addition to these two elements, which exert a positive effect on investment decisions, our analysis also confirms the positive effect of our proxy for the level of economic activity, i.e. the deviation of employment from its conventional level, on investment via businessmen's expectations. This particular analysis does not point to the existence of a labour constraint in the sense described in section 2 .

Furthermore, there is a negative effect of the cost of financial resources on investment. The impact is important in terms of our static relationship but not so in the case of the dynamic one. This lack of impact of the cost of external finance emphasises the role played by expectations to fuel the animal spirits. In other words, in the short run businessmen assume that the central bank would not change credit standards. In this 
context, commercial banks would be willing to issue all those loans that would be required to satisfy the share of potential buyers, which would present a feasible investment project. The feasibility and profitability of those projects that assure the repayment of the loan would be based strongly on expectations about future demand.

Finally, attention needs to be drawn to the interpretation of the effect that emanates from oil prices. A different interpretation of the impact of this variable at the sectoral/firm level and at the aggregate level should be provided. Specifically, at the aggregate level in a time horizon of 1 to 2 years, it is not possible to identify the positive effect on investment, which takes place when a firm invests to improve its efficiency in order to minimise its production costs. The one that prevails is a negative impact that was discussed above. Our model cannot capture the positive effect since it requires a longer period of time to account for it, i.e. firms need to perceive an increase in the price of the energy commodity as permanent before investing in a new technology. The negative effect that our estimates indicate captures a slowdown of profits due to the rise in the cost of the energy commodity under consideration. At the sectoral level, if we focus on the short run, what happens is that those firms that operate more oil-intensive processes have to reduce their production if they cannot pass this increase onto consumers. At the same time, those firms, which employ processes that are less intensive in oil, would increase their production by taking advantage of these new conditions in the market place. This behaviour is reasonable since businessmen would invest in response to permanent changes in the economic environment.

\section{Summary and conclusions}

This paper proposes an alternative version of the accelerator model, which takes into account other explanatory variables, such as changes in oil prices and the cost of external finance. Furthermore, the accelerator term is also reformulated in a context where uncertainty and the lack of perfect information compel firms to take into account several proxies of the level of economic activity. In our theoretical framework entrepreneurs' expectations are built according to the Keynesian notion of conventions, which helps to account for investment decisions in a world dominated by uncertainty.

Our theoretical framework is tested econometrically by means of a panel, which spans the period 1970-2010 and gathers data on 11 OECD economies. The estimates point to the accelerator term as the main explanatory element, which exerts the strongest positive 
effect on investment. Our model also highlights a positive correlation between corporate investment and households' investment. This is due to the existence of a crucial impact of the latter on demand, employment and income generation. Nevertheless, there is an inverse relationship between shocks in oil prices and capital accumulation. Our model also highlights a negative impact of uncertainty on investment decisions, since it is more difficult for businessmen to foresee the future. Finally, this study emphasises that changes in interest rates do affect investment negatively.

\section{Appendix}

Table 2

Overview of data sources

\begin{tabular}{lcc}
\multicolumn{1}{c}{ Variable } & Coverage & Data source \\
\hline $\begin{array}{l}\text { Gross Domestic Product } \\
\text { Expenditure, Gross Fixed Capital }\end{array}$ & 1960 -present & AMECO \\
Formation of Corporations & 1960 -present & AMECO \\
$\begin{array}{l}\text { Gross Fixed Capital Formation of } \\
\text { Households }\end{array}$ & 1970 -present & AMECO \\
$\begin{array}{l}\text { Unemployment Rate } \\
\begin{array}{l}\text { Mein Economic Indicators, Long- } \\
\text { term Interest Rate }\end{array} \\
\text { Oil Prices }\end{array}$ & 1960-present & AMECO \\
\hline
\end{tabular}

Note: Missing observations in the case of the long-term interest rate have been completed by using data from national statistical sources in the case of Austria, Denmark, Italy and Spain.

\section{References}

Arellano, M., 1987. Computing robust standard errors for Within-groups estimators. Oxford Bulletin of Economics and Statistics 49, 431-434.

Arellano, M., Bond, S., 1991. Some tests of specification for panel data: Monte Carlo evidence and an application to employment equations. Review of Economic Studies 58, 277-97.

Arellano, M., Bover, O., 1995. Another look at the instrumental variable estimation of error-components models. Journal of Econometrics 68, 29-51.

Arestis, P., González, A.R., Dejuán, O., 2012. Modelling accumulation: A theoretical and empirical application of the accelerator principle under uncertainty. European Journal of Economics and Economic Policies: Intervention 9, 255-275.

Arestis, P., Gonzalez-Martinez, A.R., 2014. Residential construction activity in OECD economies. The Manchester School 83, 451-474.

Arouri, M.E.H., 2011. Does crude oil move stock markets in Europe? A sector investigation. Economic Modelling 28, 1716-1725. 
Baddeley, M., 2003. Investment: Theories and analysis, Basingstoke: Palgrave Macmillan.

Baltagi, B.H., 2006. Panel data models. Mills, T.E. and Patterson, K. (eds.), Palgrave Handbook of Econometrics, vol. I, New York: Palgrave Macmillan.

Beck, N., Katz, J.N., 1995. What to do (and not to do) with time series cross-section data. American Political Science Review 89, 634-647.

Bernanke, B., Gertler, M., Gilchrist, S., 1996. The financial accelerator and the flight to quality. Review of Economics and Statistics 78, 1-15.

Chaney, T., Sraer, D., Thesmar, D., 2012. The collateral channel: How real estate shocks affect corporate investment. American Economic Review 102, 2381-2409.

Chenery, H.B., 1952. Overcapacity and the acceleration principle. Econometrica, 20, 1-28.

Chetty, R., 2007. Interest rates, irreversibility, and backward-bending investment. Review of Economic Studies 74, 67-91.

Choi, I., 2001. Unit root tests for panel data. Journal of International Money and Finance 20, 249-272.

Davidson, P., 2002. Financial markets, money and the real world. Cheltenham: Edward Elgar.

De Hoyos, R.E., Sarafidis, V., 2006. Testing for cross-sectional dependence in panel-data models. The Stata Journal 6, 482-496.

Dehn, J., 2000. Private investment in developing countries: The effects of commodity shocks and uncertainty. WPS/2000-11. Centre for the Study of African Economies.

De Manuel Aramendía, M., 2011. Market efficiency in the eu emissions trading scheme. an outlook for the third trading period. BEER No. 20. Available at: https://www.coleurope.eu/system/files_force/research-paper/beer20.pdf?download=1

De Melo Modenesi, A.; Lyrio Modenesi, R.; Oreiro, J.L.; Montani Martins, N., 2013. Convention, interest rates and monetary policy : A Post-Keynesian-French-conventionsschool approach. European Journal of Economics and Economic Policies: Intervention 10, 76-92.

Dequech, D., 2009. Institutions, social norms, and decision-theoretical norms. Journal of Economic Behaviour and Organisation 72, 70-78.

Dequech, D., 2011. Financial conventions in Keynes's theory: the stock exchange. Journal of Post Keynesian Economics 33, 469-490.

Driscoll, J., Kraay, A.C., 1998. Consistent covariance matrix estimation with spatially dependent data. Review of Economics and Statistics 80, 549-560. 
Dutt, A.K., 1984. Stagnation, income distribution and monopoly power. Cambridge Journal of Economics 8, 25-40.

Fazzari, S., Hubbard, R.G., Petersen, B., 1988. Financing constraints and corporate investment. Brookings Paper on Economic Activity 1, 141-195.

Gan, J., 2007. Collateral, debt capacity and corporate investment. Journal of Financial Economics 85, 709-734.

Gattini, L., Ganoulis, I., 2012. House price responsiveness of housing investments across major european economies. Working Paper 1461. European Central Bank.

Gete, P., 2010. Housing markets and current account dynamics. Mimeo. Georgetown University.

Hausman, J.A., 1978. Specification tests in econometrics. Econometrica 46, 1251-1271.

Hendry, D., Richard, J., 1983. The econometric analysis of economic time series. International Statistics Review 51, 3-33.

Hoechle, D., 2007. Robust standard errors for panel regressions with cross-sectional dependence. The Stata Journal 7, 281-312.

Hodrick, R.J., Prescott E.C., 1980. Postwar US business cycles: An empirical investigation. Manuscript. Carnegie-Mellon University.

Im, K. S., Pesaran, M.H., Shin, Y., 2003. Testing for unit roots in heterogeneous panels. Journal of Econometrics 115, 53-74.

Jorgenson, D.W., (1963). Capital theory and investment behaviour. American Economic Review, Vol. 53, pp. 247-259.

Keynes, J.M., 1936. The general theory of employment, interest and money. London: Macmillan.

Kilian, L., 2009. Not all oil price shocks are alike: Disentangling demand and supply shocks in the crude oil market. American Economic Review 99, 1053-1069.

Kristensen, I.P., Wawro, G., 2003. Lagging the dog? The robustness of panel corrected standard errors in the presence of serial correlation and observation specific effects. Annual Meeting of the Society for Political Methodology. University of Minnesota.

Koyck, L.M., 1954. Distributed lags and investment analysis. Amsterdam: North-Holland.

Lavoie, M., Rodríguez, G., Seccareccia, M., 2004. Similitudes and discrepancies in Post Keynesian and Marxist theories of investment: A theoretical and empirical investigation. International Review of Applied Economics 18, 127-149.

Leamer, E.E. 2007. Housing is the business cycle. NBER Working Paper No. 13428, Cambridge MA: National Bureau of Economic Research. 
Lee, I.H. Syed, M., Xueyan, L., 2012. Is China over-investing and does it matter? IMF Working Paper No. 12/277, Washington, D.C.: International Monetary Fund.

Merton, R.K., 1968. Social theory and social structure. New York: Free Press.

Millard, S., Shakir, T., 2013. Oil shocks and the UK economy: The changing nature of shocks and impact over time. Working Paper No. 476. Bank of England.

Miller, N., Peng, L., Sklarz, M., 2011. House prices and economic growth. Journal of Real Estate Finance and Economics 42, 522-541.

Myers, S., 1984. The capital structure puzzle. Journal of Finance 39, 575-592.

Newey, W. K., West, K.D., 1987. A simple, positive semi-definite, heteroskedasticity and autocorrelation consistent covariance matrix. Econometrica 55, 703-708.

Nickell, S., Nunziata, L., 2002. Unemployment in the OECD since the 1960s. What do we know?. Paper Presented at the Conference entitled Unemployment. London School of Economics.

Ouchida, Y., Goto, D., 2014. Do emission subsidies reduce emission? In the context of environmental R\&D organization. Economic Modelling, 36, 511-516.

Pesaran, M.H., 2004. General diagnostic tests for cross section dependence in panels. Cambridge Working Papers in Economics No. 0435. University of Cambridge.

Reboredo, J.C., Rivera-Castro, M.A., 2013. A wavelet decomposition approach to crude oil price and exchange rate dependence. Economic Modelling 32, 42-57.

Reed W.R., Webb R., 2010. The PCSE estimator is good - just not as good as you think. Journal of Time Series Econometrics 2, 1-26.

Shahbaz, M., Zeshan, M., Afza, T., 2012, Is energy consumption effective to spur economic growth in Pakistan? New evidence from bounds test to level relationships and Granger causality tests. Economic Modelling 29, 2310-2319.

Shiller, R.J., 2007. Understanding Recent Trends in House Prices and Home Ownership. NBER Working Paper no. 13553, National Bureau of Economic Research.

Skott, P., Zipperer, B., 2010. An empirical evaluation of three Post-Keynesian models. University of Massachusetts Working Paper 2010-08.

Spada., 2009. British professions today: The state of the sector. London: Spada.

StataCorp., 2009. Stata Statistical Software: Release 11. College Station, TX: StataCorp LP.

Stockhammer, E., Grafl, L., 2010. Financial uncertainty and business investment. Review of Political Economy 22, 551-568. 
The Economist., 2012. Spain's banking system. Teetering, 2 June.

Wooldridge, J.M., 2002. Econometric analysis of cross section and panel data, Cambrigde: MIT Press. 


\title{
Revisiting the accelerator principle in a world of uncertainty: Some empirical evidence
}

\author{
Philip Arestis ${ }^{\mathrm{a}}$, and Ana Rosa Gonzalez-Martinez ${ }^{\mathrm{b}}$ \\ ${ }^{a}$ Department of Land Economy, University of Cambridge, Cambridge CB3 9EP; (e- \\ mail:pa267@cam.ac.uk) \\ ${ }^{\mathrm{b}}$ Cambridge Econometrics, Cambridge CB1 2HT; (e-mail: agm@ camecon.com)
}

\begin{abstract}
This contribution builds on the accelerator model to produce an investment function in which employment and households' investment are used as proxies for economic activity. This analysis identifies a positive correlation between corporate investment in fixed assets and households' investment in dwellings. Using a panel of 11 OECD countries for the period 1970-2010, the results also confirm that oil prices and interest rates may dampen firms' investment in fixed assets. An interesting feature of this investment function is that it accounts for uncertainty.
\end{abstract}

Keywords: Investment, Uncertainty, Accelerator, Panel Data

JEL Classification: B22, C23, E22 